ISSN: 2146-3042

DOI: $10.25095 /$ mufad.438760

\title{
Maddi Duran Varlık Alımı Duyurularının Pay Getirilerine Etkisi: BİST Dokuma, Giyim Eşyası ve Deri Sektörü Üzerine Bir Araştırma
}

\author{
Neilan SOYLU* \\ Hasan UYGURTÜRK ${ }^{* *}$ \\ Turhan KORKMAZ***
}

\begin{abstract}
$\ddot{O Z Z E T}$
Varlığını sürdürmek, büyümek ve piyasa değerini artırmak gibi amaçlarla kurulan işletmeler için yatırım kararları bu amaçların gerçekleştirilmesinde ayrı bir öneme sahiptir. Işsletmenin uzun vadeli nakit aksşlarını etkileyen yatırım kararlarında ise maddi duran varlıklar önemli bir yer tutmaktadır. İşletmenin gelecekte elde edeceği kazanma gücü işletme sahip ve yöneticilerini olduğu kadar yatırımcıları da ilgilendirmektedir. Bu çalı̧̧mada payları Borsa İstanbul'da işlem gören dokuma, giyim eşyası ve deri sektörü işletmelerinin maddi duran varlık alım duyurularının pay getirisine etkisinin olay çalışması ile araştırılması amaçlanmıştır. Çalışma sonucunda 2010 Ocak2017 Aralık döneminde analiz kapsamına alınan işletmelerin maddi duran varlık alımı duyurularının pay getirilerine etkisinin olmadiğ tespit edilmiştir.
\end{abstract}

Anahtar Kelimeler: Maddi duran varlık alımı, olay çalışması, Borsa İstanbul.

JEL Sınıflandırması: G11, G14.

The Effect of Fixed Assets Purchase Announcements on Stock Returns: A Research on Textile, Wearing Apparel and Leather Industry

\section{ABSTRACT}

For businesses set up with the purpose of survival, growth and market value maximization investment decisions have been of critical importance in realizing their objectives. Fixed assets are important aspects in investment decisions affecting the long term cash flows of enterprises. The ability to generate cash flows is of great interest not only for managers and the owners of the companies but for the investors as well. The aim of the present study was to investigate the effect of fixed assets purchase announcements on stock returns of textile, wearing apparel and leather industry firms traded on Borsa Istanbul using event study method. The results show that fixed assets purchase announcements of the firms included in the analysis during the period of January, 2010-December, 2017 have no significant effect on stock returns.

Keywords: Fixed assets purchase, event study, Borsa Istanbul.

Jel Classification: G11, G14.

\footnotetext{
* Dr. Öğretim Üyesi Neilan SOYLU, Karabük Üniversitesi, İşletme Fakültesi, neilansoylu@ karabuk.edu.tr

${ }^{* *}$ Doç. Dr. Hasan UYGURTÜRK, Karabük Üniversitesi, İşletme Fakültesi, hasanuygurturk@karabuk.edu.tr

${ }^{* * *}$ Prof. Dr. Turhan KORKMAZ, Mersin Üniversitesi, İ̈BF, tkorkmaz@mersin.edu.tr
} 


\section{GíRiş̧}

İşletme varlıkları içinde yer alan maddi duran varlıklar işletmenin gelecekteki nakit akışları üzerinde büyük bir etkide bulunabilmektedir. Bu nedenle maddi duran varlıklara yönelik alınacak kararlar işletme yöneticilerinin verdikleri kararlar arasında en önemli olanlarının başında gelmektedir.

İşletmelerin sahip olduğu varlıklar arasında önemli bir bölümü oluşturan maddi duran varlıklar, mal veya hizmet üretimi veya arzında kullanılmak, başkalarına kiraya verilmek veya idari amaçlar çerçevesinde kullanılmak üzere elde tutulan ve bir dönemden daha fazla kullanımı öngörülen fiziki kalemlerdir (TMS16, md.6). Arazi ve arsalar, binalar, makina ve tesisler, taşıtlar gibi maddi duran varlıkların işletmelerin esas faaliyetlerinde doğrudan kullanılmaları nedeniyle, bu varlıklara yapılacak yatırımların firmaların varlıklarını devam ettirebilmeleri ve rekabet koşullarına uyum sağlayarak üstünlük elde etmeleri açısından yaşamsal önem taşır. Maddi duran varlıklar, işletmelerin aktifleri arasında büyük bir yüzdeye sahip olmaktadırlar. TCMB 2015 sektör bilançolarına göre Tarım, Ormancılık ve Madencilik işletmelerinde $\% 41$, Metal Ana sanayinde $\% 35$, İmalat sanayinde $\% 26$ 'ya ulaşan maddi duran varlıklar, doğrudan ülkenin gelecekteki üretim kapasitesini etkilemektedir.

Üretim kapasitesini etkileyen maddi duran varlıklar, ekonominin büyümesi ve istihdam yaratılması sürecine de olumlu katk1 yapmaktadır (Güven, 2013: 2). Bu nedenle, son derece kısıtlı, yoğun bir ulusal ve uluslararası rekabetin etkisi altında olan işletmelerin yatırım firsatlarını ortaya koymaları, dikkatle analiz etmeleri ve firma değerini maksimize edecek doğru yatırım kararları alabilmeleri stratejik öneme sahiptir (Alper, 2007: 71). Maddi duran varlıklara yapılacak yatırımların uzun süreli ve büyük harcamalar gerektirmesi, sabit varlıkların bir bütünlük ve bölünmezlik göstermesi, firmanın likidite ve risk derecesini önemli ölçüde etkilemesi nedeniyle yatırım kararlarının firmanın gelecekteki başarısını etkileyen en önemli kararlar olduğu söylenebilir (Akgüç, 2010: 318). Bu doğrultuda yatırım kararlarının verilmesinde iki önemli kriter öne çıkmaktadır. Bunlar; karın maksimizasyonu ve firmanın piyasa değerinin maksimizasyonudur. İlk kritere göre, eğer firma sahiplerinin net karları artar ise fiziksel varlık işletmeye değer katmış olacaktır. İkinci kritere göre, eğer işletme sahiplerinin hisselerinin değeri artarsa, başka bir ifadeyle, varlığın maliyetinden daha fazlası işletmenin piyasa değerine eklenirse varlık yine değer yaratmış olacaktır (Modigliani ve Miller, 1958: 262).

Bu çalışmada, Borsa İstanbul'da payları işlem gören ve dokuma, giyim eşyası ve deri sektöründe faaliyet gösteren işletmelerin maddi duran varlık alım duyurularının pay getirisine etkisinin araştırılması amaçlanmıştır. Bu amaç doğrultusunda, 2010 Ocak ayından 2017 Aralık ayına kadar olan 8 yıllık süreçte ilgili işletmelerin paylarının günlük kapanış verileri dikkate alınarak olay çalışması gerçekleştirilmiş ve ulaşılan sonuçlar yorumlanmıştır.

\section{MADDİ DURAN VARLIK YATIRIMLARININ ÖZELLIKLERİ}

İşletmelerde yatırım kararları bütüncül bir stratejik yaklaşım çerçevesinde ele alınmaktadır. Çünkü ekonomik ömrü uzun olan bu varlıklardan beklenen faydanın sağlanması zaman alabilmekte ve bu süreç içerinde makroekonomik belirsizlikler ve finansal sorunlar ortaya çıkabilmektedir. Öte yandan, işletme bu varlıklara gereğinden fazla yatırım yaparsa, gelecekte yüksek harcamalar yüklenmiş olacak ve firmanın faaliyet riski yükselecektir. 
Yetersiz yatırım ise firmayı eksik kapasite sorunuyla karşı karşıya bırakacaktır; bu da firmanın karlılığını ve pazardaki konumunu olumsuz etkileyecektir. Maddi duran varlıkların zamanında işletmenin kapasite artırımı ihtiyaçlarına cevap verebilmesi, yapılacak yatırımların zamanlaması ve satın alınan varlıkların kalitesi ile doğrudan ilişkilidir. Bilindiği gibi, makine ve ekipmanların doğası gereği, üretim süreci uzun sayılabilecek bir süre gerektirir; bu süreyi ve olası gecikmeleri önceden tahmin ederek, ekipmanları tam zamanında hazır bulundurmak yine işletmenin stratejik planının bir parçasıdır (Weston ve Copeland, 1992: 301).

Maddi duran varlıklar, üretim sürecinde bir girdi olarak kullanılmaktadır. Bu nedenle, söz konusu değerlere yapılacak yatırım ile firmanın üretim planları arasında çok yakın bir ilişki vardır. Üretim planları, firmanın ürettiği mal veya hizmetlerin satış tahminlerine dayalı yapıldığından, duran varlıklara yatırım talebi, türetilmiş bir istemdir. Gelecek dönemlerle ilgili satış tahminlerinde yapılan bir hata aşırı veya noksan yatırım yapılması sonucunu doğurmaktadır (Akgüç, 2010: 319).

Maddi duran varlık yatırımları genellikle büyük miktarda harcamalar gerektirmektedir. Ayrıca, bizzat yatırımın kendi maliyeti yanında bazı ek maliyetler de söz konusu olabilmektedir. Yeni bir makineye uyum sağlayabilmesi için işgücünün eğitiminden kaynaklanan maliyetler ya da yeni makinenin kurulumunda tesis üretiminin durması gibi uyum maliyetleri de yatırım kararları açısından önem taşımaktadır (Güven, 2013: 3). Dolayısıyla, bu süreçte işletmelerin fon ihtiyaçlarını karşılamak için finansman kaynaklarının ulaşılabilirliği ve uygun kredi koşullarının önceden sağlanmış olması gerekmektedir. Özellikle, sermaye piyasalarına erişimi daha zor olan küçük ve orta boy işletmelerde, sınırlı olan fon kaynaklarını yanlış bir projeye bağlanmış olması telafisi olmayan, firmanın varlığını tehlikeye atabilecek sorunlara yol açabilmektedir (Brigham ve Houston, 2004: 532).

Öte yandan, ağır makine ve ekipmanların yatırımlarının sektöre veya işletmeye özgü olması, bu varlıkların farklı bir sektörde veya işletmede verimli kullanılamaması, diğer bir deyişle batık maliyet içermeleri nedeniyle geri dönülemez yatırımlar oldukları söylenebilir (Pindyck, 1991: 1111). Geri dönülmez maddi duran varlıklara sahip olan işletmeler makroekonomik değişkenlerde meydana gelecek değişmelere daha duyarlıdırlar. Çünkü sahip oldukları atıl kapasite nedeniyle ekonomik canlanma dönemlerinde ek yatırımlar yapmadan üretimi (çıktıyı) artırabilmektedirler. Defter değeri yüksek olan bu firmalar, piyasadaki dalgalanmalardan daha kolay etkilenebilmekte, dolayısıyla daha yüksek sistematik riske maruz kalabilmektedirler (Cooper, 2006).

Maddi duran varlık yatırımlarının işletmeye yüklediği risklerin yanında pekçok avantajı da beraberinde getirmektedir. Bu varlıkların teminat olarak gösterilme özelliklerinden dolayı firma daha uygun koşullarda borçlanabilmekte ve daha fazla yatırım yapabilmektedir. Özellikle finansal sorunlarla karşılaşan işletmelerde, yatırım kararları büyük ölçüde maddi duran varlıklara bağlı olabilmektedir (Almeida ve Campello, 2007). Dietrich (2007)'ye göre düşük maddi duran varlık oranı firmanın borçlanma olanakları üzerinde olumsuz etki yaratmaktadır. Dolayısıyla, maddi duran varlıkların işletmenin sermaye yapısı üzerinde de etkili olduğu söylenebilmektedir (Harc, 2015: 215).

İşletmenin varlıklarının yapısı finansal sıkıntı maliyetlerini de doğrudan etkilemektedir. Arazi, ekipman ve diğer maddi duran varlıklara sahip olan işletmeler, diğer işletmelere göre daha düşük finansal sıkıntı maliyetleri ile karşı karşıya kalmaktadırlar 
(Daskalakis ve Psillaki, 2008: 90). Maddi duran varlık oranının yüksek olması firmanın iflası veya yeniden yapılanması durumunda ortaya çıkacak olan tasfiye değeri üzerinde doğrudan etkilidir. Bununla birlikte, tasfiye durumunda bu varlıkların daha kolay el değiştirmesi nedeniyle, yüksek Maddi Duran Varlık (MDV) oranı firmaya borç verenler açısından da arzu edilen bir durumdur (Campello ve Giambona, 2012).

\section{LITERATÜR ARAŞTIRMASI}

Firmaların yatırım politikalarını inceleyen çalışmalar arasında, yatırım harcamaları duyuruları ile pay fiyatı arasındaki ilişkinin yönü yatırımların kalitesi, süresi, firma büyüklüğü ve ait olduğu sektör gibi faktörlere bağlı olarak değiştiği görülmektedir. Pay piyasaları, daha çok beklentinin satın alındığı piyasalar olduğundan, bu tür açıklamalar, gelecekte daha yüksek kazanç beklentisine paralel olarak, ilgili firmanın pay fiyatını, diğer bir ifadeyle piyasa değerini olumlu etkileyebilir (Kaderli ve Demir, 2009: 47). Öte yandan, temsil teorisi veya kurumsal yatırımcılar teorisi çerçevesinde, piyasanın uzun vadeli yatırımlara negatif tepki verebileceğini öne sürülmektedir (Woolridge ve Snow, 1990: 355). McConnell ve Muscarella (1985), 1975-1981 yıllarını kapsayan çalışmalarında, ABD'de 658 şirketin gelecek yıllarda yapılacak sermaye harcamalarını açıkladıkları tarihlerde, pay fiyatı tepkisini araştırmışlardır. Sonuç olarak, sanayi şirketlerinde, yatırım harcamalarında artış (azalış) duyurularının pozitif (negatif) anormal getiriye neden olduğu bulgusuna ulaşmışlardır. Woolridge ve Snow (1990), ABD'de 248 işletmenin stratejik yatırım kararları duyurularının piyasaya etkisini incelemişlerdir. Stratejik yatırım kararlarının dört ayrı başlık altında (ortak girişim, AR-GE projeleri, sermaye harcamaları, ürün çeşitlendirme kararları) sınıflandırılan çalışmanın sonuçları hissedar değeri maksimizasyonu hipotezi ile uyumlu olduğu tespit edilmiştir. Kapasite artırımı, fabrika modernizasyonu gibi sermaye harcamaları duyurularının pay fiyatına etkisinin istatistiksel olarak anlamlı olduğu sonucuna ulaşılmıştır. Ayrıca, maddi duran varlık ve AR-GE yatırımları için sonuçların küçük ve büyük projeler için farklılaşmadığını, böylece şirketlerin iyi analiz edilmiş, uzun vadeli yatırımlar yaptıklarında piyasa tarafından cezalandırılmadıkları belirtilmiştir.

Chung vd. (1998), 1981-1995 yılları arasında ABD’de işlem gören şirketlerin sermaye harcamalarına ilişkin 308 duyurunun piyasaya etkisini araştırmışlardır. Sonuçlar, piyasa tepkisinin firmanın ait olduğu endüstriden çok büyüme olanaklarıyla orantılı olduğunu ortaya koymuştur. Burton vd. (1999), 1989-1991 yılları arasında Birleşik Krallıkta faaliyet gösteren firmaların maddi duran varlık yatırımları ile pay fiyatı arasındaki ilişkiyi incelemişlerdir. Çalışma sonucunda, hemen nakit üretmesi beklenen yatırımların pay fiyatını etkilediği tespit edilmiştir. Jones vd. (2004), 1991-1996 yılları arasında Birleşik Krallıkta borsaya kote şirketlerin yatırım duyurularının pay fiyatına etkisini incelemişlerdir. 402 yatırım duyurusunun ele alındığı çalışmada piyasa tepkisinin duyuru kategorisine ve şirket büyüklüğüne göre değiştiği vurgulanmıştır. Gelecekte başka yatırım fırsatları yaratan duyuların, diğer yatırım duyurularına göre etkisinin daha fazla olduğu, küçük şirketler tarafindan yapılan duyuruların büyük şirketlere göre daha etkili olduğu sonucuna ulaşılmıştır. $\mathrm{Bu}$ bulgular, yatırımcıların iyi yatırım ile kötü yatırım arasında ayırım yapabildiğini, genel olarak iyi yatırım yapan şirketleri ödüllendirdiklerini işaret etmektedir (Chan, 1995: 81). Suresh vd. (2005), 2004-2005 dönemi için Hindistan Bombay Borsasında işlem gören şirketlerin stratejik karar duyurularının pay piyasasına etkilerini araştırmışlardır. Çalışma sonucunda pay piyasasının kurumsal stratejik karar duyurularına negatif tepki verdiği bulgusu elde edilmiştir. 
Chen (2006), 1989-1999 döneminde ABD piyasasında yatırım harcamalarına ilişkin 246 duyuruyu incelediği çalışmasında, yoğunlaşmış şirketler tarafından yapılan duyuruların çeşitlendirilmiş şirketlere göre pay fiyatını daha fazla etkilediği sonucuna ulaşmıştır. Benzer bir çalışma ile Bhana (2008), 1995-2004 döneminde Güney Afrika piyasasında benzer sonuçlar ortaya koymuştur. Gupta ve Banga (2009), 2004-2006 döneminde Hindistan piyasasında sermaye harcamalarına ilişkin 493 duyurunun pay fiyatına etkisinin duyurunun yapıldığ 1 gün pozitif ve anlamlı olduğunu ortaya koymuşlardır.

Kaderli ve Demir (2009), firmaların "yatırım kararı" aldıklarına ilişkin duyurularının, ilgili firmaların pay getirileri üzerinde herhangi bir etkiye sahip olup olmadığını, olay etüdü yöntemiyle ve sektörel bazda araştırmışlardır. Elde edilen bulgular, İMKB'de, yatırım kararı duyurularının ilgili firmaların pay getirilerini olumlu yönde etkilediğini ortaya koymuştur.

Özbebek vd. (2011), Temmuz 2007 - Şubat 2011 dönemini kapsayan çalışmalarında Borsa İstanbul'da işlem gören şirketlerin stratejik yatırım kararlarına (sermaye harcamaları) ilişkin duyurularının pay piyasasına etkisini araştırmışlardır. Çalışma kapsamında 27 şirketin, 37 sermaye harcamaları duyurusu incelenmiş, bu duyuruların şirketin pay fiyatlarına pozitif etkisi saptanamamıştır. Elde edilen sonuçlar, piyasa tepkisinin daha çok yatırımların kalitesine bağlı olduğu şeklinde yorumlanmıştır.

Eyüboğlu ve Bulut (2016), Ocak 2003-Aralık 2012 dönemi için BİST-30'da işlem gören şirketlerce duyurulan haberlerin hisse performansına etkisini araştırmışlardır. Analiz sonucunda, yatırımcıların en çok operasyonel, finansal ve yeniden yapılanmaya ilişkin haberlere karşı duyarlı olduğunu ortaya koymuştur.

Elbir ve Kandır (2017)'ın çalışmalarında, payları Borsa İstanbul'da işlem gören demirçelik sektöründeki 7 şirketin 2005 ve 2015 yılları arasındaki döneme ait 23 adet yatırım duyurusu incelenmiştir. Sonuçlar, demir-çelik şirketlerinin yatırım duyurularının pay getirilerinde anormal getiriye neden olduğunu göstermiştir.

\section{4. ÇALIŞMANIN KAPSAMI VE YÖNTEM}

Bu çalışmada, Borsa İstanbul'da payları işlem gören dokuma, giyim eşyası ve deri sektörü işletmelerinin maddi duran varlık alımı (MDV) duyurularının pay getirilerine etkisinin "olay çalışması" (event-study) yöntemiyle analiz edilmesi amaçlanmıştır. Diğer bir ifadeyle, maddi duran varlık alımı duyurularının pay piyasasında anormal getiriler elde edilmesine imkan sağlayıp sağlamadığı araştırılmıştır. Yapılan literatür araştırması sonucunda, gerçekleştirilen çalışmaların genellikle "yatırım duyuruları" geneli üzerine odaklandığı, yatırımları kategorilere ayırarak alt yatırım duyurularının etkisinin incelendiği çalışmaların sayısının ise oldukça az olduğu kanısına varılmıştır. Bundan hareketle, bu çalışmada işletmelerin yaptıkları çeşitli yatırımlar arasında maddi duran varlık alımları ele alınarak ilgili alana yönelik katkı sağlanacağı düşünülmüştür.

Analiz dönemi için belirlenen 2010 Ocak ayından 2017 Aralık ayına kadar olan süreçte, payları Borsa İstanbul'da işlem gören dokuma, giyim eşyası ve deri sektöründeki 5 işletmenin toplam 11 adet MDV alımı duyurusu çalışmanın temelini oluşturmuştur. BİST'de payları işlem gören dokuma, giyim eşyası ve deri sektöründeki işletme sayısının daha fazla olmasına karşın söz konusu analiz döneminde MDV duyuları bulunmayan işletmeler kapsam 
dışı bırakılmıştır. Ayrıca analiz dönemindeki MDV duyurularından bazıları, duyuru tarihinden önceki zaman diliminin olay çalışması için yetersiz olmasından dolayı çalışmaya dahil edilememiştir. Analiz kapsamına alınan işletmeler Tablo 1'de yer almaktadır.

Tablo 1. Çalışma Kapsamına Alınan İşletmeler

\begin{tabular}{ll}
\hline BÍST Kodu & İşletme Adı \\
\hline BLCYT & Bilici Yatırım Sanayi ve Ticaret A.Ş. \\
KRTEK & Karsu Tekstil Sanayii ve Ticaret A.Ş. \\
RODRG & Rodrigo Tekstil Sanayi ve Ticaret A.Ş. \\
ROYAL & Royal Halı İplik Tekstil Mobilya Sanayi ve Ticaret A.Ş. \\
YATAS & Yataş Yatak ve Yorgan Sanayi ve Ticaret A.Ş. \\
\hline
\end{tabular}

Tablo 1'deki işletmelerin pay fiyatları ile BİST 100 Endeksi kapanış verileri Finnet 2000 Plus programı aracılığıyla elde edilmiştir. İşletmelerin 2010 Ocak-2017 Aralık dönemindeki MDV alımı duyuruları Kamuyu Aydınlatma Platformundan (KAP, 2017) elde edilmiş ve söz konusu duyurulara ilişkin bilgiler Tablo 2'de gösterilmiştir.

Tablo 2. 2010 Ocak-2017 Aralık Dönemindeki BİST Dokuma, Giyim Eşyası ve Deri Sektöründeki İşletmelerin MDV Alımı Duyuruları

\begin{tabular}{|c|c|c|c|c|c|}
\hline $\begin{array}{l}\text { Duyuru } \\
\text { Tarihi }\end{array}$ & $\begin{array}{l}\text { BİST } \\
\text { Kodu }\end{array}$ & Özet Bilgi & MDV Niteliği & $\begin{array}{l}\text { Toplam Alım } \\
\text { Bedeli }\end{array}$ & $\begin{array}{c}\text { Alımın Amacı ve } \\
\text { Ortaklığın Faaliyetlerine } \\
\text { Etkileri }\end{array}$ \\
\hline 21.04 .2010 & YATAS & $\begin{array}{l}\text { Yatırım amaçlı } \\
\text { arsa satın alınması }\end{array}$ & Arsa & $14.840 .000 \mathrm{TL}$ & $\begin{array}{l}\text { Yatırım amaçlı alım, üretim } \\
\text { ve satış ağının } \\
\text { genişletilmesi. }\end{array}$ \\
\hline 6.02 .2012 & BLCYT & Makina alımı & $\begin{array}{l}\text { Sentetik } \\
\text { Tekstürize İplik } \\
\text { Makinası }\end{array}$ & 780.000 USD & $\begin{array}{l}\text { Yeni iplik hattı kurularak } \\
\text { üretime geçilmesi. }\end{array}$ \\
\hline 10.01 .2013 & BLCYT & $\begin{array}{l}\text { Gayrimenkul } \\
\text { alımı }\end{array}$ & Mesken & 1.478.250 USD & $\begin{array}{l}\text { Büro olarak kullanılmak } \\
\text { üzere, ortaklığın } \\
\text { faaliyetlerine etkisi yoktur. }\end{array}$ \\
\hline 11.02 .2013 & BLCYT & İlave tesis yapımı & $\begin{array}{l}\text { Boya - Apre } \\
\text { makina teçhizatı } \\
\text { ve bina için } \\
\text { gereken inşaat } \\
\text { malzemeleri }\end{array}$ & $\begin{array}{l}\text { 1.720.000 Euro } \\
\text { makina teçhizat } \\
\text { alımı, } 180.000 \\
\text { Euro bina inşaat } \\
\text { yatırımı }\end{array}$ & $\begin{array}{l}\text { Boya-Apre tesisinin üretim } \\
\text { kapasitesini arttırmak; } \\
\text { Şirketin faaliyetine etkisi } \\
\text { ise, net satış hasılatını } 2013 \\
\text { yılı için \%5 daha sonraki } \\
\text { yıllarda \%25 ilave etkisi } \\
\text { olacağ } 1 \text { hesaplanmaktadır. }\end{array}$ \\
\hline 11.06 .2013 & KRTEK & $\begin{array}{l}\text { Yatırım yapılması } \\
\text { ile ilgili yönetim } \\
\text { kurulu kararı }\end{array}$ & İmalat Makinası & & $\begin{array}{l}\text { Yatırımın } 2013 \text { yılı sonunda } \\
\text { başlayıp, } 2014 \text { yılı ilk } \\
\text { yarısında tamamlanması } \\
\text { planlanmaktadır. }\end{array}$ \\
\hline 7.03 .2014 & ROYAL & $\begin{array}{l}\text { Royal Halı A.Ş. } \\
\text { halı üretim tesisi } \\
\text { mevcut üretim } \\
\text { kapasitesi artışı }\end{array}$ & $\begin{array}{l}7 \text { Adet Van de } \\
\text { Wiele Halı } \\
\text { Tezgahı }\end{array}$ & 6.500.000 Euro & $\begin{array}{l}\text { Halı üretim tesisi kapasite } \\
\text { artırımı }\end{array}$ \\
\hline 2.06 .2014 & ROYAL & $\begin{array}{l}\text { Royal Halı A.Ş. } \\
\text { iplik üretim tesisi } \\
\text { mevcut kapasite }\end{array}$ & $\begin{array}{l}2 \text { adet iplik } \\
\text { üretim hattı }\end{array}$ & 7.300.000 Euro & $\begin{array}{l}\text { İplik üretim tesisi kapasite } \\
\text { artışı }\end{array}$ \\
\hline
\end{tabular}




\begin{tabular}{|l|l|l|l|l|l|}
\hline $\begin{array}{c}\text { Duyuru } \\
\text { Tarihi }\end{array}$ & \multicolumn{1}{|c|}{$\begin{array}{c}\text { BíST } \\
\text { Kodu }\end{array}$} & \multicolumn{1}{|c|}{ Özet Bilgi } & MDV Niteliği & $\begin{array}{c}\text { Toplam Alım } \\
\text { Bedeli }\end{array}$ & $\begin{array}{c}\text { Alımın Amacı ve } \\
\text { Ortaklığın Faaliyetlerine } \\
\text { Etkileri }\end{array}$ \\
\hline 20.04 .2015 & YATAS & $\begin{array}{l}\text { Maddi duran } \\
\text { varlı edinilmesi }\end{array}$ & Mesken & $130.000 \mathrm{TL}$ & $\begin{array}{l}\text { Borca mahsup, etkisi olması } \\
\text { beklenmemektedir. }\end{array}$ \\
\hline 17.05 .2016 & YATAS & $\begin{array}{l}\text { Maddi duran } \\
\text { varlı edinilmesi }\end{array}$ & Kargir İşyeri & $3.450 .000 \mathrm{TL}$ & $\begin{array}{l}\text { Borca mahsup, etkisi olması } \\
\text { beklenmemektedir. }\end{array}$ \\
\hline 29.09 .2016 & YATAS & & Mesken & $1.000 .000 \mathrm{TL}$ & $\begin{array}{l}\text { Borca mahsup, etkisi olması } \\
\text { beklenmemektedir. }\end{array}$ \\
\hline 14.02 .2017 & RODRG & & Büro & $550.000 \mathrm{TL}$ & $\begin{array}{l}\text { Yatırım amaçlı olup } \\
\text { gerekirse ileriki dönemlerde } \\
\text { ofis olarak kullanılabilir }\end{array}$ \\
\hline
\end{tabular}

Kaynak: KAP (2017), https://www.kap.org.tr/tr/bildirim-sorgu, (Erişim Tarihi: 05.12.2017).

Çalışmada analiz yöntemi olarak "olay çalışması” kullanılmıştır. Olay çalışması yöntemi finans araştırmalarında çok kullanışlı olması nedeniyle literatürde oldukça geniş kullanım alanı bulmuştur. Bir olayın herhangi bir finansal değişken üzerindeki etkisini ölçmede kullanılan olay çalışması sıklıkla piyasa etkinliğini test etmekte kullanılan bir araçtır; eğer finansal piyasalar yarı güçlü formada etkin ise duyuru günü yeni bilgi ile fiyatlarda anlık bir tepkiden sonra, ilerleyen işlem günlerinde bunun devam etmemesi beklenmektedir (Brooks, 2014: 634).

Olay çalışması ile ilgili olarak tek bir model olmamakla birlikte çoğu finansal olay çalışmasında birbirini izleyen dört adım bulunmaktadır (Sakarya, 2011: 153). Bunlar; (1) Olayın tanımlanması, (2) Olay penceresinin tanımlanması, (3) Olayın etkilerinin değerlendirilmesi ve (4) Modelin kurulup test edilerek sonuçların değerlendirilmesidir. Bu yöntem 3 ana zaman dilimini kapsamaktadır (Benninga, 2014: 333). Bunlar; tahmin penceresi, olay penceresi ve olay sonrası penceresi olarak siralanmaktadır. Tahmin penceresi, pay hareketlerinin "normal" olarak gözlemlenebileceği dönemi ifade etmektedir. Bu dönem Armitage (1995)'e göre günlük veri için 100 ile 300 gün arası olabilmektedir. Bu çalışmada tahmin dönemi 126 gün olarak belirlenmiştir. "Olay günü” tespitinde duyurunun yapıldığ saat dikkate alınmış, saat 17.00 'ye kadar yapılan duyurular için aynı gün, saat 17.00 'den sonra yapılan duyurular için ertesi gün baz alınmıştır. Olay penceresi ise açıklamanın yapıldığ 1 olay gününün 5 gün öncesi ve 5 gün sonrası $(-5 ;+5)$ olarak belirlenmiştir.

Olay çalışmasının amacı, bir olayın piyasaya ilk duyurulduğu tarih etrafinda fazla bir getirinin (excess return) elde edilip edilemeyeceği tespit edilmesidir. Fazla getiriler, ilgili haberlerin piyasaya duyurulmaması halinde elde edilecek olan normal getirilerden yüksek veya düşük olan getirilerdir (Kaderli ve Demir, 2009:50). Fazla getiriyi hesaplayabilmek için önce tahmin penceresinde normal getiri tahmin edilir. Normal getiri tahmini için kullanılan modeller ortalama sabit getiri modeli, piyasa modeli ve faktör modelleridir (MacKinley, 1997: 17-20). Bu çalışmada, piyasa modeli kullanılmış ve aşağıdaki gibi hesaplanmıştır (MacKinley, 1997; Campbell vd. 1997).

$$
\begin{array}{ll}
R_{i t}=\alpha_{i}+\beta_{i} * R_{m t}+\varepsilon_{i t} & \\
\mathrm{E}(\varepsilon \text { it }=0) & \operatorname{var}\left(\varepsilon_{i t}\right)=\sigma_{s}^{2}
\end{array}
$$


Denklem (1)'de, $R_{\mathrm{it}}, \mathrm{t}$ gününde gerçekleșen i payının getirisini, $R_{m t}, \mathrm{t}$ gününde gerçekleşen piyasa getirisini, hesaplanan $\alpha$ değeri piyasa modelindeki regresyon doğrusunun sabit terimini, $\beta$ piyasa getirisinin eğimini, sıfır ortalamalı hata terimini göstermektedir.

Olay penceresindeki dönem için ( $\tau$ günü) i payı için anormal getiri ise aşağıdaki şekilde hesaplanmaktadır (Mackinley, 1997).

$$
A R_{i \tau}=R_{i \tau}-\hat{\alpha}_{i}-\hat{\beta}_{i} * R_{m t}
$$

Olay çalışmasında $\mathrm{N}$ sayıda firma veya $\mathrm{N}$ sayıda olay incelendiğinde olayın genel etkilerinin görülebilmesi için anormal getirilerin (AR) toplulaştırılması gerekmektedir (MacKinley, 1997, Çukur vd. 2008, Brooks, 2015). Bunun için, N sayıda firmanın anormal getirilerin (AR) aritmetik ortalaması hesaplanmaktadır.

$$
A A R_{\tau}=\frac{1}{N} * \sum_{i=1}^{N} A R_{i \tau}
$$

Denklem (3)'te N, ele alınan firma sayısını; $\tau$, olay penceresindeki günü $(-5,-4, \ldots . .4$, 5), $\mathrm{i}$ ise $\mathrm{i}$ hissesini göstermektedir.

AAR $\tau$ 'nin varyansı Denklem (4)'deki gibi hesaplanmaktadır.

$$
\operatorname{var}\left(A A R_{\tau}\right)=\frac{1}{N^{2}} * \sum_{i=1}^{N} \operatorname{var}\left(A R_{i t}\right)
$$

Yukarıdaki denklem aracılıyla hesaplanan (AAR $\tau$ )'nin istatistiksel olarak anlamlı olup olmadığını test etmek için kullanılan t istatistiği aşağıdaki gibi hesaplanmaktadır.

$$
\text { St. } A A R_{\tau}=A A R_{\tau} / \sqrt{\operatorname{var}\left(A A R_{\tau}\right)}
$$

Daha sonra olay penceresindeki dönem için kümülatif ortalama anormal getiri (CAAR) aşağıdaki gibi hesaplanır.

$$
C A A R_{\tau 1 \tau 2}=\sum_{\tau=\tau 1}^{\tau 2} A A R_{\tau}
$$

CAAR'ın varyansı ise Denklem (7)'de gösterilmiştir.

$$
\operatorname{var}\left(C A A R_{\tau 1 \tau 2}\right)=\sum_{\tau=\tau 1}^{\tau 2} \operatorname{var}\left(A A R_{\tau}\right)
$$

CAAR'ın test istatistiği ise aşağıdaki gibi hesaplanır.

$$
\text { St. } \text { CAAR }_{\tau 1 \tau 2}=C^{C A A R_{\tau 1 \tau 2}} / \sqrt{\operatorname{var}\left(C^{\prime} A A R_{\tau 1 \tau 2}\right)}
$$

Çalışmada olay penceresinde ortalama anormal getirilerin (AAR) ve kümülatif ortalama anormal getirinin (CAAR) anlamlı olarak sıfırdan farklı olup olmadığı test edilmiştir. Bunun için hipotezler aşağıdaki gibi kurulmuştur. 
$\mathrm{H}_{0 \mathrm{~A}}: \mathrm{AAR}=0$; Olay penceresinde ortalama anormal getiriler sıfıra eşittir. Bu durumda MDV alımlarının pay getirisine etkisi yoktur.

$\mathrm{H}_{1 \mathrm{~A}}: \mathrm{AAR} \neq 0$; Olay penceresinde ortalama anormal getiriler sıfıra eşit değildir. $\mathrm{Bu}$ durumda MDV alımlarının pay getirisine etkisi vardır.

$\mathrm{H}_{0 \mathrm{~B}}: \mathrm{CAAR}=0$; Olay penceresinde kümülatif anormal getiriler sıfıra eşittir.

$\mathrm{H}_{1 \mathrm{~B}}$ : CAAR $\neq 0$; Olay penceresinde kümülatif anormal getiriler sıfıra eşit değildir.

\section{BULGULAR}

Analiz kapsamına alınan işletmelerin MDV alım duyurularının yapıldı̆̆ itibaren 5 gün önce ve 5 gün sonraki zaman dilimi için günlük fiili getiri oranları hesaplanmış ve bu getiri oranları kullanılarak işletmelere ilişkin ortalama anormal getiriler $\left(\mathrm{AAR}_{\mathrm{t}}\right)$ ve kümülatif anormal getiriler $\left(\mathrm{CAAR}_{t}\right)$ tespit edilerek Tablo 3 'de gösterilmiştir.

Tablo 3. Olay Tarihinden 5 Gün Öncesi ve 5 Gün Sonrası için Hesaplanan Ortalama Anormal Getiriler ve Kümülatif Ortalama Anormal Getiriler

\begin{tabular}{ccccc}
\hline Olay Penceresi & AAR & $\mathbf{t}$ istatistiği & CAAR & t istatistiği \\
\hline-5 & 0.007 & 0.963 & 0.007 & 0.278 \\
-4 & 0.009 & 1.111 & 0.016 & 0.599 \\
-3 & -0.001 & -0.174 & 0.015 & 0.549 \\
-2 & -0.004 & -0.454 & 0.011 & 0.417 \\
-1 & 0.007 & 0.900 & 0.018 & 0.677 \\
$\mathbf{0}$ & $\mathbf{- 0 . 0 0 3}$ & $\mathbf{- 0 . 4 2 4}$ & $\mathbf{0 . 0 1 5}$ & $\mathbf{0 . 5 5 5}$ \\
1 & 0.005 & 0.588 & 0.019 & 0.725 \\
2 & -0.001 & -0.096 & 0.019 & 0.697 \\
3 & -0.011 & -1.392 & 0.008 & 0.295 \\
4 & 0.011 & 1.442 & 0.019 & 0.711 \\
5 & -0.003 & -0.440 & 0.016 & 0.584 \\
\hline
\end{tabular}

Tablo 3'de yer alan AAR, MDV alım duyurularının olay penceresindeki her bir gün için ortalama piyasa değeri üzerindeki etkisini belirlemek için kullanılmaktadır. Tablo 3'e göre MDV alım duyuruları için en düşük ortalama getiri $t+3$ gününde, en yüksek ortalama getiri ise $\mathrm{t}+4$ gününde gerçekleşmiştir. Duyuru günü $(\mathrm{t}=0)$ ise ortalama $\% 0,3$ 'lik bir negatif getiri ortaya çıkmıştır. Ancak hesaplanan bu getiriler istatistiksel açıdan anlamlı bulunmamıştır. Dolayısıyla bu durumda $\mathrm{H}_{0 \mathrm{~A}}$ hipotezi kabul edilirken $\mathrm{H}_{1 \mathrm{~A}}$ hipotezi ret edilmektedir.

İşletmeler tarafından yapılan duyuruların toplam etkisini gösteren kümülatif anormal getirilerin $\left(\mathrm{CAAR}_{\mathrm{t}}\right)$ değerlerinin olay penceresi içerisindeki tüm günlerde sıfirdan farklı ve pozitif değerli olduğu görülmektedir. Olay tarihinden sonraki günlerde olaydan önceki 
günlere kıyasla genel olarak daha yüksek hesaplanan CAAR değerlerinin hiçbiri istatistiki olarak anlamlı bulunmamıştır. Buna göre $\mathrm{H}_{0 \mathrm{~B}}$ olarak ifade edilen olay penceresinde kümülatif anormal getiriler sıfıra eşittir hipotezi kabul edilmektedir. Dolayısıyla MDV alım duyurularının, analiz kapsamına alınan işletmelerin pay getirileri üzerinde bir etki oluşturmadığ 1 tespit edilmiştir. Elde edilen bulgular Özbebek vd. (2011) ve kısmen Kaderli ve Demir (2009)'in çalışmalarıyla benzerlik göstermektedir.

Grafik 1. Dokuma, Giyim Eşyası ve Deri Sektöründe Faaliyet Gösteren İşletmelerin Ortalama ve Kümülatif Anormal Getirilerinin Olay Penceresindeki Hareketleri

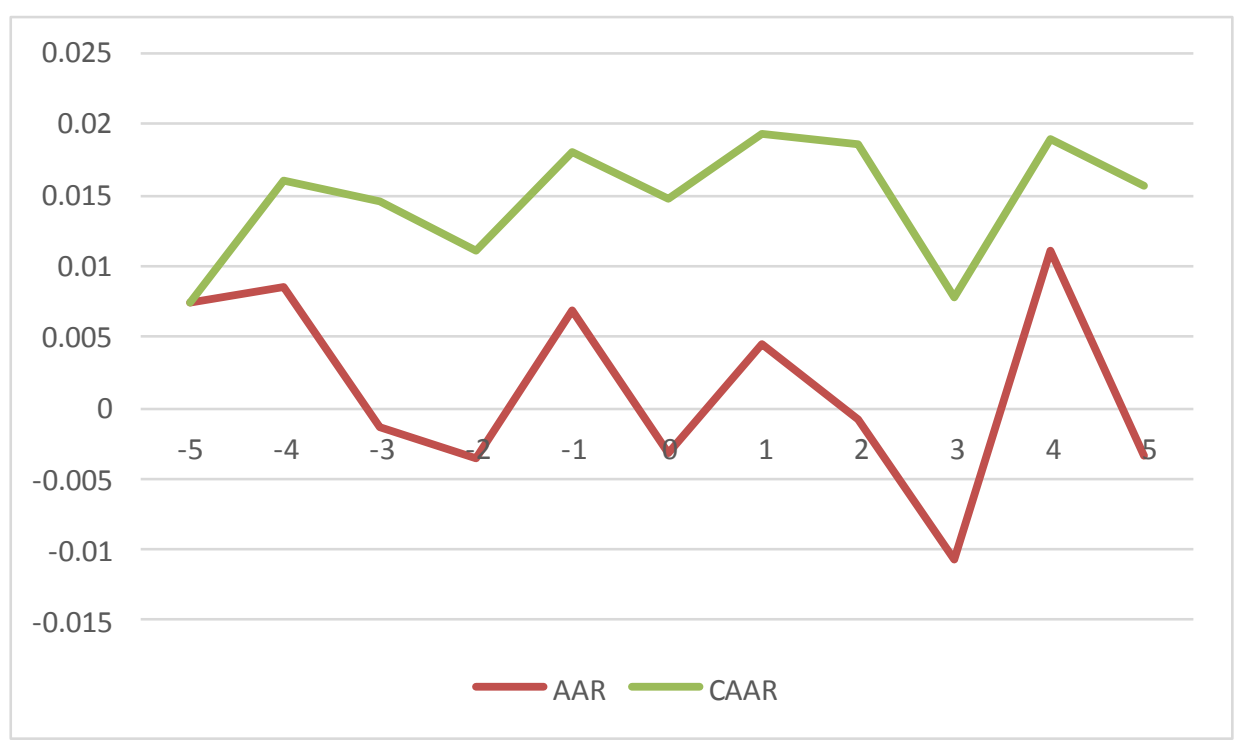

Grafik 1'de dokuma, giyim eşyası ve deri sektöründeki işletmelerin paylarının olay penceresindeki ortalama (AAR) ve kümülatif (CAAR) anormal getirilerinin grafiği yer almaktadır. Buna göre ortalama anormal getiriler olay gününden önceki ve sonraki dönemlerde hem negatif hem de pozitif değerlere sahip olarak dalgalı bir seyir izlemiştir. Ortalama anormal getiriler duyurunun yapıldığ 1 tarihten $(\mathrm{t}=0)$ sonraki $\mathrm{t}+3$ de en düşük, $\mathrm{t}+4$ de de en yüksek seviyeye ulaşarak dalgalı seyrini sürdürmüştür. MDV alımı duyurularının yapıldığg tarihe kadar kümülatif ortalama anormal getiriler ise değişken pozitif değerlere sahip olarak dalgalanma göstermiştir. Kümülatif ortalama anormal getiriler duyurunun yapıldığ 1 tarihten itibaren $\mathrm{t}+1$ ve $\mathrm{t}+2$ de yükselişe geçmiş, ancak $\mathrm{t}+3$ de hızlı bir düşüş sergilemiş ve sonraki günlerde ise eski seviyelerine yakın değerler elde etmiştir.

\section{SONUÇ}

Hızla gelişen ve rekabetin yoğun olduğu ekonomi dünyasında işletmelerin varlıklarını sürdürmelerinde ve büyümelerinde yeni yatırımların önemi büyüktür. Ayrıca işletmeyle beraber ülke ekonomisinin kalkınmasının temel faktörlerinden biri de gerçekleştirilecek 
yatırımlardır. İşletme büyüklüğünün önemli göstergelerinden biri olan aktif unsurlar içinde en önemli yere sahip olanların başında ise maddi duran varlıklar gelmektedir. Maddi duran varlıklar işletmelerin uzun dönemli yatırımları olarak görüldüğünden işletmenin gelecekteki nakit akışları ve başarısı üzerinde kayda değer bir etkiye sahiptir. Dolayısıyla işletmenin temel amaçları arasında ilk sıralarda yer alan işletmenin piyasa değerinin maksimizasyonunu sağlamada maddi duran varlıklar etkili olmaktadır.

Bu çalışmada payları Borsa İstanbul'da işlem gören ve dokuma, giyim eşyası ve deri sektöründe faaliyette bulunan işletmelerin, 2010 Ocak ayından 2017 Aralık ayına kadar olan süreçteki maddi duran varlık alımı (MDV) duyurularının işletmelerin pay getirilerine etkisinin "olay çalışması" (event-study) yöntemiyle analiz edilmiştir. Çalışmada işletmelerin MDV alımı duyurularının kamuya ilan tarihinden (olay tarihi) $-5,+5$ gün aralığ 1 olay penceresi olarak belirlenmiş ve günlük veriler kullanılarak işlemler gerçekleştirilmiştir. Bu doğrultuda işletmelerin MDV alımı duyuru tarihleri etrafındaki günlerde piyasanın ilgili duyurulara yönelik olan tepkisini ölçmek amacıyla anormal ve kümülatif anormal getiriler hesaplanmıştır. Anormal getirilerin hesaplanmasında piyasa modeli kullanılmıştır.

Çalışma sonucunda analiz kapsamına alınan işletmelerin MDV alımı duyurularının pay getirilerine etkisinin olmadığı tespit edilmiştir. Buna göre 2010 Ocak - 2017 Aralık döneminde dokuma, giyim eşyası ve deri sektöründeki işletmelerin MDV alımı duyuruları öncesinde ve sonrasında $(-5,+5)$ istatistiki olarak anlamlı anormal getiriler elde etmek mümkün olmamıştır. Ulaşılan sonuçlar doğrultusunda BİST dokuma, giyim eşyası ve deri sektöründeki işletmelerin olay penceresi içindeki ortalama anormal getirileri ile kümülatif anormal getirileri sıfirdan farklı olmadığından $\mathrm{H}_{0 \mathrm{~A}}$ ve $\mathrm{H}_{0 \mathrm{~B}}$ hipotezleri kabul edilmiştir. Dolayısıyla ilgili sektörde MDV alımı duyurularından yararlanarak anormal getiri elde edilememektedir.

Sonuç olarak, elde edilen bulgular potansiyel/mevcut pay piyasası yatırımcıları ile araştırmacılara piyasa etkinliği hakkında önemli bilgiler sunmaktadır. MDV alımı duyurularının istatistiki düzeyde anlamlı anormal getiri sağlamaması pay piyasası yatırımcılarının yatırım kararlarını etkileyebilecek kayda değer bir bilgi niteliği taşımaktadır. Gerçekleştirilen bu çalışma, diğer sektörlerdeki işletmelerin MDV alımı duyurularının pay getirilerine olan etkisini incelemek isteyen araştırmacılara da bir örnek olabilecektir.

\section{KAYNAKLAR}

Akgüç, Öztin (2010), Finansal Yönetim, 8. Baskı, Avcılol Basım Yayın, İstanbul.

Almeida, Heitor - Campello, Murillo (2007), "Financial Constraints, Asset Tangibility, and Corporate Investment", Review of Financial Studies, 20 (5), pp. 1429-1460.

Alper, Değer (2007), “Sermaye Bütçelemesi ve Reel Opsiyonlar”, Uludağ Üniversitesi İktisadi ve İdari Bilimler Fakültesi Dergisi, XXVI (1), ss. 69-86.

Armitage, Seth (1995), "Event Study Methods and Evidence on Their Performance”, Journal of Economic Surveys, 8 (4), pp. 25-52.

Benninga, Simon (2014), Financial Modelling, 4th edition, The MIT Press, Cambridge. 
Bhana, N. (2008), "The Market Reaction to Capital Expenditure Announcements", Investment Analysts Journal, 68, pp. 53-64.

Brigham, Eugene F. - Houston, Joel F. (2004), Fundamentals of Financial Management, 10th Edition, South-Western, Cincinnati.

Brooks, Chris (2014), Introductory Econometrics for Finance, 3rd Edition, Cambridge University Press, Cambridge.

Burton, Bruce M. - Lonie, Alasdair A. - Power, David M. (1999), "The Stock Market Reaction to Investment Announcements: The Case of Individual Capital Expenditure Projects", Journal of Business Finance \& Accounting, 26, pp. 681-709.

Campbell, John Y. - Lo, Andrew W. - MacKinlay, A. Craig (1997), The Econometrics of Financial Markets, Princeton University Press, New Jersey.

Campello, Murillo - Giambona, Erasmo (2012), "Real Assets And Capital Structure”, NBER Working Paper No. 18147, Cornell University, New York.

Chan, Su Han, Gau, George W. - Wang, Ko (1995), "Stock Market Reaction to Capital Investment Decisions: Evidence from Business Relocations", Journal of Financial and Quantitative Analysis, 30 (1), pp. 81-100.

Chen, Sheng-Syan (2006), "The Economic Impact of Corporate Capital Expenditures: Focused Firms Versus Diversified Firms”, Journal of Financial and Quantitative Analysis, 41 (2), pp. 341-355.

Chung, Kee H. - Wright, Peter - Charoenwong, Charlie (1998), "Investment Opportunities and Market Reaction to Capital Expenditure Decisions", Journal of Banking \& Finance, 22 (1), pp. 41-60.

Cooper, Ilan (2006), "Asset Pricing Implications of Non-Convex Adjustment Costs and Irreversibility of Investment", Journal of Finance, 61 (1), pp. 139-170.

Çukur, S. - Eryiğit, M. - Duran, S. (2008), "Sendikasyon ve Sekürütizasyon Kredileri Anlaşmalarının Borçlanan Bankaların Hisse Fiyatlarına Etkileri”, İktisat, İşletme ve Finans, 23(264), ss. 58-78.

Daskalakis, Nikolaos - Psillaki, Maria (2008), "Do Country of Firm Explain Capital Structure? Evidence from Smes in France and Greece", Applied Financial Economics, 18 (2), pp. 87-97.

Dietrich, Diemo (2007), “Asset Tangibility and Capital Allocation”, Journal of Corporate Finance, 13 (5), pp. 995-1007.

Elbir, Gözde - Kandır, Serkan Yılmaz (2017), "Yatırım Duyurularının Pay Getirileri Üzerindeki Etkisinin İncelenmesi: Demir-Çelik Sektörü Örneği’", Ekonomi Bilimleri Dergisi, 9 (1), ss. 16-32. 
Eyüboğlu, Kemal - Bulut, Halil İbrahim (2016), "Şirketlere Özgü Haberlerin Hisse Performansına Etkisi: Bist-30 Şirketleri Örneği”, International Journal of Economic and Administrative Studies, 16, ss. 113-138.

Gupta, Amitabh - Banga, Charu (2009), "Capital Expenditure Decisions and the Market Value of the Firm", The IUP Journal of Applied Finance, 15 (12), pp. 5-17.

Güven, Aytekin (2013), "Yatırımlar, Belirsizlik ve Piyasa Yapısı: Kavramsal Bir İnceleme”, Afyon Kocatepe Üniversitesi İ̈BF Dergisi, 15 (1), ss. 1-23.

Harc, Martina (2015), “The Relationship Between Tangible Assets and Capital Structure of Small and Medium-Sized Companies in Croatia", Econviews, 28 (1), pp. 213-224.

Jones, Edward - Danbolt, J. - Hirst, Ian (2004), "Company Investment Announcements and The Market Value of The Firm", The European Journal of Finance, 10 (5), pp. 437452 .

Kaderli, Yusuf - Demir, Sezgin (2009), "Yatırım Kararı Duyurularının Hisse Senedi Getirileri Üzerindeki Etkisinin Ölçülmesi: Olay Etüdü Yöntemi”, Mali Çözüm Dergisi, 91, ss. 45-66.

KAP (2017), https://www.kap.org.tr/tr/bildirim-sorgu, (05.12.2017).

MacKinlay, A. Craig (1997), "Event Studies in Economics and Finance", Journal of Economic Literature, 35 (1), pp. 13-39.

McConnell, John J. - Muscarella, Chris J. (1985), "Corporate Capital Expenditure Decisions and the Market Value of the Firm", Journal of Financial Economics, 14 (3), pp. 399422 .

Modigliani, Franco - Miller, Merton H. (1958), "The Cost of Capital, Corporation Finance and the Theory of Investment", The American Economic Review, 48 (3), pp. 261-297.

Özbebek, Ayşegül - Canikli, Seda - Aytürk, Yusuf (2011), "Does Turkish Stock Market React to Public Announcements of Major Capital Expenditures?”, Procedia Social and Behavioral Sciences, 24, pp. 928-934.

Pindyck, Robert S. (1991), "Irreversibility, Uncertainty, and Investment", Journal of Economic Literature, 29 (3), pp. 1110-1148.

Sakarya, Şakir (2011), “IMMKB Kurumsal Yönetim Endeksi Kapsamındaki Şirketlerin Kurumsal Yönetim Derecelendirme Notu ve Hisse Senedi Getirileri Arasındaki İlişkinin Olay Çalışması (Event Study) Yöntemi ile Analizi”, Zonguldak Karaelmas Üniversitesi Sosyal Bilimler Dergisi, 7 (13), ss. 147-162.

Suresh, Srinivasan - Thenmozhi, M. - Vijayaraghavan, P. (2006), Stock Market Reaction to Corporate Strategic Decisions. Indian Institute of Capital Markets 9th Capital Markets Conference Paper. Available at SSRN: https://ssrn.com/abstract=873987 or http://dx.doi.org/10.2139/ssrn.873987. 
TMS 16, http://www.resmigazete.gov.tr/eskiler/2005/12/20051231-54.htm, (10.12.2017).

Weston, Fred J. - Copeland, Thomas E. (1992), Managerial Finance, Ninth Edition, Dryden Press International Edition.

Woolridge, J. Randall - Snow, Charles C. (1990), "Stock Market Reaction to Strategic Investment Decisions”, Strategic Management Journal, 11 (5), pp. 353-363. 